\title{
Efficacy and safety of sofosbuvir plus ribavirin for Korean patients with hepatitis C virus genotype 2 infection: A retrospective multi-institutional study
}

\author{
Young Min Kim', Suk Bae Kim1', Il Han Song', Sae Hwan Lee², Hong Soo Kim², Tae Hee Lee ${ }^{3}$, Young Woo Kang ${ }^{3}$, \\ Seok Hyun Kim ${ }^{4}$, Byung Seok Lee ${ }^{4}$, Hee Bok Chae ${ }^{5}$, Myeong Jun Song ${ }^{6}$, Ji Woong Jang ${ }^{7}$, Soon Young Ko ${ }^{8}$, and \\ Jae Dong Lee ${ }^{8}$ \\ 'Department of Internal Medicine, Dankook University College of Medicine, Cheonan; ${ }^{2}$ Department of Internal Medicine, Soonchunhyang \\ University College of Medicine, Cheonan; ${ }^{3}$ Department of Internal Medicine, Konyang University College of Medicine, Daejeon; ${ }^{4}$ Department \\ of Internal Medicine, Chungnam National University College of Medicine, Daejeon; ${ }^{5}$ Department of Internal Medicine, Chungbuk \\ National University College of Medicine, Cheongju; ${ }^{6}$ Department of Internal Medicine, College of Medicine, Catholic University of Korea, \\ Daejeon; ${ }^{7}$ Department of Internal Medicine, Eulji University Hospital, Daejeon; ${ }^{8}$ Department of Internal Medicine, Konkuk University \\ School of Medicine, Chungju, Korea
}

Background/Aims: Sofosbuvir plus ribavirin is a standard treatment for patients infected with chronic hepatitis $C$ virus (HCV) genotype 2 in Korea. The purpose of this study was to examine the efficacy and safety of this treatment in Korean patients with chronic HCV genotype 2 infection.

Methods: We retrospectively analyzed clinical data of patients treated with sofosbuvir plus ribavirin for chronic HCV genotype 2 from May 2016 to December 2017 at eight hospitals located in the Daejeon-Chungcheong area.

Results: A total of 172 patients were treated with sofosbuvir plus ribavirin. Of them, 163 patients completed the treatment, and 162 patients were tested for sustained virologic response 12 weeks after treatment discontinuation (SVR12). Mean age was 59.6 \pm 12.3 years (27-96), and 105 (64.4\%) patients were female. Of the total patients, 49 (30.1\%) were diagnosed with cirrhosis, and 31 of them were treated for 16 weeks. Sofosbuvir plus ribavirin was the first-line treatment for 144 (88.3\%) patients. Eleven (6.7\%) patients were intolerant to previous interferon-based treatment. Eight (5.0\%) patients relapsed after interferon-based treatment. HCV RNA non-detection rate at 4, 8, and 12 weeks was 97.5\%, $99.1 \%$, and $99.3 \%$, respectively, and SVR12 was $98.8 \%$ (161/163). During treatment, $18(11.0 \%)$ patients had to reduce their administrated dose of ribavirin because of anemia. One patient stopped the treatment because of severe anemia. Other adverse events, including dizziness, indigestion, and headache, were found in 26 (16.0\%) patients.

Conclusions: A 12-16 week treatment with sofosbuvir plus ribavirin is remarkably effective and well tolerated in Korean patients with chronic HCV genotype 2 infection. (Clin Mol Hepatol 2018;24:311-318)

Keywords: Sofosbuvir; Ribavirin; Hepatitis C virus; Korea

\section{Abbreviations:}

DAA, direct acting antivirals; HCC, hepatocellular carcinoma; HCV, Hepatitis C virus; LC, liver cirrhosis; LLOQ, lower limit of quantification; PCR, polymerase chain reaction; SVR12, sustained virologic response 12 weeks after treatment discontinuation

\section{Corresponding author : Suk Bae Kim}

Department of Internal Medicine, Dankook University College of Medicine, 119 Dandae-ro, Dongnam-gu, Cheonan 31116, Korea

Tel: +82-41-550-3910, Fax: +82-41-556-3256

E-mail: dryakson@hanmail.net

https://orcid.org/0000-0002-6857-9624 


\section{Study Highlights}

Sofosbuvir is a novel direct acting antivirals used to treat patients with chronic hepatocellular carcinoma genotype 2 infection. In this multicenter study, 12-16 weeks treatment with sofosbuvir plus ribavirin resulted in sustained virologic response 12 weeks after treatment discontinuation rates of 98.8\% in treatment-naive and treatment-experienced Korean patients with or without liver cirrhosis. Sofosbuvir plus ribavirin, an interferon-free regimen, was well tolerated.

\section{INTRODUCTION}

Hepatitis C virus (HCV) infection is one of the major causes of chronic hepatitis, liver cirrhosis (LC), hepatocellular carcinoma (HCC), and liver-related mortality. Approximately $10 \%$ of LC and $12-17 \%$ of HCC are attributed to chronic HCV infection in Korea, while the prevalence of chronic HCV infection in adults is less than $1 \%{ }^{1,2}$ This low rate of HCV infection can be attributed to anti-HCV screening tests being performed before blood transfusions. However, recent outbreaks of HCV in healthcare facilities have become a highly concerning public health problem. ${ }^{3}$

Previous standard therapy for patients with HCV genotype 2 infection was based on the combination of pegylated interferon with weight-based dosage of ribavirin. This treatment was shown to result in a sustained virologic response 12 weeks after treatment discontinuation (SVR12) in 70-80\% of patients treated for chronic HCV genotype 2 infection. ${ }^{4,5}$ The drawbacks of this treatment include severe adverse reactions, discomfort due to the injection, and long treatment duration. Recently, pegylated interferon-based therapy is no longer recommended as the first-line treatment since direct acting antivirals (DAA) were developed..$^{6-8}$

Sofosbuvir (SOVALDI ${ }^{\circledR}$, Sovaldi, Gilead Sciences, Seoul, Korea) is a novel DAA used to treat patients with chronic HCV genotype 2 infection with or without decompensated LC. Four clinical phase 3 studies, looking into the effects of a combination of sofosbuvir plus ribavirin on chronic HCV genotype 2 infection in Western countries have shown variable SVR12 rates ranging from 86 to $97 \%{ }^{9-11}$ Still, this combination is not more recommended than other treatments for HCV genotype 2 infection by the American associations for the study of liver diseases (AASLD) and European associations for the study of liver diseases (EASL). ${ }^{6,7}$ However, SVR12 rates obtained with sofosbuvir plus ribavirin in Asian countries ranges from 95 to $100 \%$, which is higher compared to Western countries. ${ }^{12,13}$ A combination of sofosbuvir and ribavirin is the only possible treatment for HCV genotype 2 infection in Korea since exclusive insurance coverage started in September 2015. However, there have been few reports of real-world clinical studies, and data regarding this treatment in Korean patients remains limited.
The purpose of this retrospective study was to examine the efficacy and safety of a 12-16 weeks treatment with sofosbuvir plus ribavirin in Korean patients with chronic HCV genotype 2 infection.

\section{MATERIALS AND METHODS}

\section{Patients}

We retrospectively analyzed clinical data from patients treated with sofosbuvir plus ribavirin for chronic HCV genotype 2 from May 2016 to December 2017 at eight hospitals located in the DaejeonChungcheong area. Sofosbuvir was administered orally at a dose of $400 \mathrm{mg}$ once daily. Ribavirin was administered orally twice daily, with doses determined according to body weight $(1,000 \mathrm{mg}$ daily in patients with a body weight of $<75 \mathrm{~kg}$, and 1,200 mg daily in patients with a body weight of $\geq 75 \mathrm{~kg}$ ). We included the patients who were 18 years of age or older and had chronic infection with HCV genotype 2 with detectable serum HCV RNA. The patients who did not reach test for SVR12, not followed up to the end of treatment, expired due to non-liver disease were excluded.

A total of 172 patients were treated with sofosbuvir plus ribavirin, 9 of them were excluded (not reach test for SVR12, 7 patients; follow-up loss, 1 patient; expire due to non-liver disease, 1 patient) and 163 patients were finally enrolled (Fig. 1). LC was diagnosed if confirmed by abdominal sonography, computed tomography, or histology. The cirrhosis was classified as either compensated or decompensated by calculating the patient's Child-Pugh score. Enrolled patients were divided into the treatment naïve group, treatment failure group (including null response, partial response, virologic breakthrough, relapse after previous treatment), and intolerant group (discontinued pegylated interferon treatment because of adverse events). The definition of virologic response followed the Korean associations for the study of liver diseases (KASL) guideline. ${ }^{8}$ Adverse events, HCV RNA non-detection rate and SVR12 were analyzed. This protocol was approved by the institutional review board or independent ethics committee at each hospital. We did not request informed consent to the patients because this study used only 
Treated with SOF plus RBV ( $n=172)$

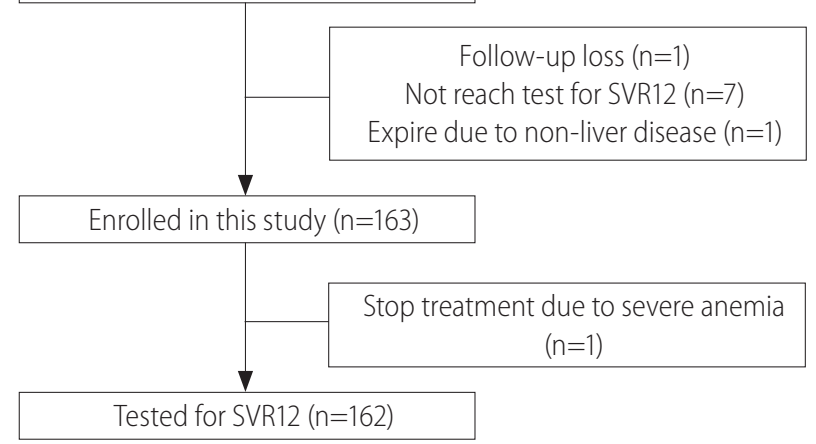

Figure 1. Flow chart summarizing patient selection. Finally, 163 patients were enrolled and completed the treatment. Only 1 patient stopped the treatment due to severe anemia. SOF, sofosbuvir; RBV, ribavirin; SVR12, sustained virologic response at post-treatment week 12 .

clinical data obtained after patients had agreed to the treatment before its initiation.

\section{Clinical and laboratory assessments}

Virologic tests were performed at 4, 8, and 12 weeks during and 12 weeks after treatment discontinuation. We calculated each patient's Child-Pugh score and divided the patient population into a compensated and a decompensated LC group in order to assess the difference in treatment efficacy on different types of cirrhosis. Adverse events were identified by reviewing medical records and additional information (their onset time, severity, duration, etc.) were confirmed through discussion with co-authors at each site. Ribavirin dose reduction for anemia followed the generalized principle. When hemoglobin dropped below $10 \mathrm{~g} / \mathrm{dL}$ on treatment, ribavirin dose reduction to $600 \mathrm{mg} /$ day was performed. But some patients took same ribavirin dose if the patients had no symptoms and the hemoglobin level decreased mildly below $10 \mathrm{~g} / \mathrm{dL}$. When hemoglobin dropped below $8.5 \mathrm{~g} / \mathrm{dL}$, ribavirin was discontinued.

\section{Measurement of HCV RNA and assessment of treatment efficacy}

HCV RNA was measured using a real-time polymerase chain reaction (PCR) assay at each site. The lower limit of quantification (LLOQ) of HCV RNA was $15 \mathrm{IU} / \mathrm{mL}$. Virologic breakthrough was defined as an increase of HCV RNA $>1 \log _{10}$ from nadir or HCV RNA $\geq$ LLOQ after a measurement below LLOQ. SVR12 was de- fined as HCV RNA levels below the lower limit of quantitation (LLOQ; $15 \mathrm{IU} / \mathrm{mL}$ ) 12 weeks after treatment discontinuation.

\section{Statistical analyses}

The efficacy and safety analyses included all enrolled patients who received at least one dose of sofosbuvir plus ribavirin. Data was expressed as mean \pm standard deviation (SD). The Chi-square test or Student's $t$-test were used for univariate analyses. We evaluated variables with $P<0.05$ at univariate analysis using multivariate logistic regression analysis. For all analysis, two-sided $P$-values were calculated, and the results were considered statistically significant at $P<0.05$. Statistical analysis was performed using IBM SPSS Statistics 23 (IBM Corp., Armonk, NY, USA).

\section{RESULTS}

\section{Baseline characteristics of the patients}

A total of 163 patients including 58 (35.6\%) male patients and $105(64.4 \%)$ female patients were enrolled. Mean age of the entire population was $59.6 \pm 12.3$ years and the oldest patient was 96 years. Cirrhosis was present at baseline in $49(30.1 \%)$ patients and absent in 114 (69.9\%) patients. Among patients presenting with cirrhosis, $2(4.1 \%)$ showed decompensated cirrhosis and 31 (63.3\%) were treated for 16 weeks with sofosbuvir plus ribavirin. Additionally, 144 (88.3\%) patients were treatment-naiive, 8 (5.0\%) failed from the interferon-based treatment, and $11(6.7 \%)$ did not tolerate pegylated interferon plus ribavirin treatment (Table 1).

\section{Adverse events}

Adverse events during treatment were reported in 26 (16.0\%) patients. Dizziness (13 patients, 8.0\%) was the most common adverse event out of them. Fatigue (6 patients, 3.7\%) was the second most common adverse event. Indigestion, epigastric soreness and an itching sensation were reported in $3(1.8 \%)$ patients, respectively. Skin rashes and headaches were reported in $2(1.2 \%)$ patients, respectively. Generalized weakness, nausea, diarrhea, fever, myalgia and anorexia were reported in only $1(0.6 \%)$ patient, respectively (Table 2 ).

Treatment discontinuation because of adverse events was rare among patients receiving sofosbuvir plus ribavirin regimens. Only one 82 years old male patient stopped the treatment after 2 weeks because of severe anemia although he received a blood transfusion 
after admission. He presented no $\mathrm{LC}$ and had no treatment history. Except him, all other patients who were affected by adverse events completed the treatment and achieved SVR12.

During treatment, anemia below hemoglobin $10 \mathrm{~g} / \mathrm{dL}$ was developed in 25 patients (15.3\%). Of them, 5 patients showed severe anemia below hemoglobin $8.5 \mathrm{~g} / \mathrm{dL}$. Ribavirin dose due to anemia was reduced in $18(11.0 \%)$ patients. Other patients had same dose of ribavirin because they showed slightly decreased hemoglobin levels below $10 \mathrm{~g} / \mathrm{dL}$ and did not complain of dizziness. Of $25 \mathrm{pa}$ tients, female was 23 patients and 10 patients showed cirrhotic liver. Their mean age was $68.1 \pm 11.5$ years old. Multivariate analysis showed that female sex (odds ratio, 7.85; 95\% confidence interval [CI], 1.78-34.65; $P=0.007$ ), older age than 60 years (odds ratio, 4.64; $95 \% \mathrm{Cl}, 1.74-12.34 ; P=0.002$ ) were predictable factors for anemia development.

\section{Biochemical response}

We analyzed mean alanine aminotransferase (ALT) levels to know the biochemical response of sofosbuvir plus ribavirin treatment on chronic hepatitis C. Before treatment, the mean ALT levels were $56.3 \pm 64.4 \mathrm{IU} / \mathrm{L}$. After 4, 8 and 12 weeks treatment, the mean ALT

Table 1. Baseline characteristics of the enrolled patients

\begin{tabular}{|c|c|}
\hline Variables & Value \\
\hline Total (n) & 163 \\
\hline Male $(n, \%)$ & $58(35.6)$ \\
\hline Female (n, \%) & $105(64.4)$ \\
\hline Age (years) & $59.6 \pm 12.3$ \\
\hline AST (IU/L) & $59.6 \pm 50.4$ \\
\hline ALT (IU/L) & $56.3 \pm 64.4$ \\
\hline HCV RNA (IU/mL) & $2,040,138 \pm 4,137,403$ \\
\hline LC (n, \%) & $49(30.1)$ \\
\hline Compensated & $47(95.9)$ \\
\hline Decompensated & $2(4.1)$ \\
\hline \multicolumn{2}{|l|}{ Treatment duration (n, \%) } \\
\hline 12 weeks treatment & $18(36.7)$ \\
\hline 16 weeks treatment & $31(63.3)$ \\
\hline Naive $(n, \%)$ & $144(88.3)$ \\
\hline Intolerant to PEG-IFN (n, \%) & $11(6.7)$ \\
\hline Treatment failure (n, \%) & $8(5)$ \\
\hline
\end{tabular}

Values are presented as mean \pm SD or $n(\%)$ unless otherwise indicated. SD, standard deviation; AST, aspartate aminotransferase; ALT, alanine aminotransferase; HCV, hepatitis C virus; LC, liver cirrhosis; PEG-IFN, pegylated interferon. levels became $22.5 \pm 16.1 \mathrm{IU} / \mathrm{L}, 22.6 \pm 17.7 \mathrm{IU} / \mathrm{L}$ and $24.3 \pm 17.0 \mathrm{IU} / \mathrm{L}$, respectively. Finally, the mean ALT levels were $21.3 \pm 13.4 \mathrm{IU} / \mathrm{L}$ at 12 weeks after treatment discontinuation (Fig. 2).

In order to know ALT normalization rate of sofosbuvir plus ribavirin, we analyzed 69 patients who showed ALT levels higher than $40 \mathrm{IU} / \mathrm{L}$. After 4, 8 and 12 weeks treatment, 76.8\% (56 patients), $85.5 \%$ (59 patients) and $75.4 \%$ (52 patients) of the patients showed ALT normalization, respectively. Finally, at 12 weeks after treatment discontinuation, ALT levels of $84.1 \%$ (58 patients) became normalized (Fig. 3).

\section{Virologic efficacy}

Out of the 163 initially enrolled patients, 162 completed the treatment. One patient stopped the treatment after 2 weeks because of severe anemia. One patient had taken sofosbuvir plus ribavirin for only 8 weeks because of financial issues, but she achieved SVR12.

After 4 weeks of treatment with sofosbuvir plus ribavirin, HCV RNA was undetectable in $97.5 \%$ (153/157) of the patients. Three patients in whom HCV RNA was detectable after 4 weeks were treatment naïve and non-cirrhotic. Their HCV RNA titer at 4 weeks were $55.4 \mathrm{IU} / \mathrm{mL}, 115 \mathrm{IU} / \mathrm{mL}$, $285 \mathrm{JU} / \mathrm{mL}$, respectively. After 8 weeks of treatment, HCV RNA became undetectable in all three patients. By week 8 and 12 of treatment, 99.1\% (109/110) and 99.3\% (145/146) of the patients had an HCV RNA level inferior to $15 \mathrm{IU} / \mathrm{mL}$.

Table 2. Summary of on-treatment adverse events in 163 patients receiving sofosbuvir plus ribavirin

\begin{tabular}{lc}
\hline Event & N (\%) \\
\hline Anemia & $25(15.3)$ \\
\hline Dizziness & $13(8.0)$ \\
\hline Fatigue & $6(3.7)$ \\
\hline Indigestion & $3(1.8)$ \\
\hline Epigastric soreness & $3(1.8)$ \\
\hline Itching & $3(1.8)$ \\
\hline Skin rash & $2(1.2)$ \\
\hline Headache & $2(1.2)$ \\
\hline Generalized weakness & $1(0.6)$ \\
\hline Nausea & $1(0.6)$ \\
\hline Diarrhea & $1(0.6)$ \\
Fever & $1(0.6)$ \\
\hline Myalgia & $1(0.6)$ \\
\hline Anorexia & $1(0.6)$ \\
\hline Total & $63(38.7)$ \\
\hline
\end{tabular}


161 of $163(98.8 \%)$ patients showed SVR12 (Fig. 4). The patient who failed to achieve SVR12 after 12 weeks treatment was a 74 years old female and did not have previous treatment history. She did not present cirrhosis and was treated continuously for 12 weeks. She did not report any specific adverse event and did not require a ribavirin dose reduction.

We analyzed SVR12 according to age, sex, presence of cirrhosis, treatment history, pretreatment HCV RNA level and ribavirin dose reduction. There was minimal difference in SVR12 values due to treatment failure in 1 patient and treatment stop in 1 patient, but no statistical significance was found (Fig. 5).

\section{DISCUSSION}

Pegylated interferon-based therapy is a non-specific antiviral treatment for HCV, whereas sofosbuvir is a HCV-specific antiviral treatment that directly interferes with HCV replication as it takes places during the life-cycle of the virus. ${ }^{14}$ Sofosbuvir is especially effective against HCV genotypes 2 and 3 when it is administered in combination with weight-based ribavirin. ${ }^{910}$ Ribavirin is an oral synthetic guanosine analogue used to stop viral RNA synthesis and has antiviral properties when used against DNA and RNA viruses. ${ }^{15}$ Genotype $2 \mathrm{a}$ is the second most common genotype, accounting for $38-46 \%$ of all HCV infections in Korea. To treat it, sofosbuvir plus ribavirin is now the only available regimen in Korea. ${ }^{16-18}$

According to previous phase 3 studies conducted in Western countries, SVR12 rates in patients with chronic HCV genotype 2 infection administered sofosbuvir plus ribavirin ranged from 86 to 97\%; FUSION (86\%), POSITRON (93\%), VALENCE (93\%) and FISSION (97\%). ${ }^{9-11}$ However, according to a previous study conducted in Japan, SVR12 rates following 12 weeks of treatment with sofos-

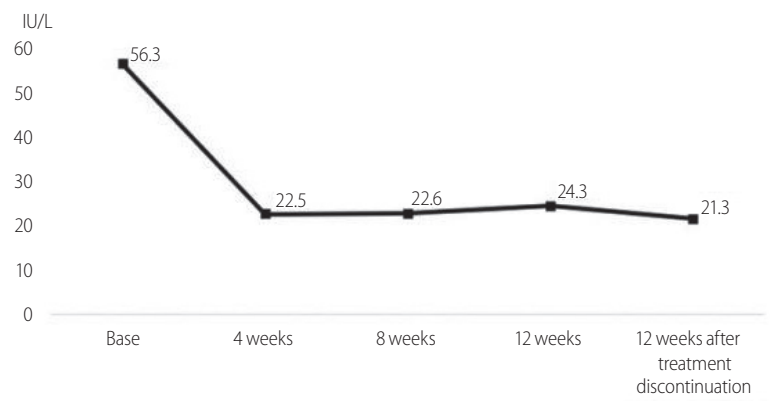

Figure 2. The changes of mean ALT level. After 4 weeks treatment, the mean ALT level was returned to normal range. After the treatment was complete, the lowest levels of ALT were observed. ALT, alanine aminotransferase. buvir plus ribavirin in treatment-naive and treatment-experienced patients with chronic HCV genotype 2 infection were $98 \%$ and $95 \%$ respectively. ${ }^{12}$ Moreover, a phase 3b study performed in Taiwan showed remarkable results in which SVR12 was 100\% in regardless of treatment history. ${ }^{13}$

Significant difference in SVR12 rates between Asian and Western patients may be explained by the fact that the studied Asian populations showed more favorable factors including younger age, lower body mass index, and higher predominance of interleukin28B (IL28B) CC allele than Western patients. ${ }^{19-24}$ The prevalence of the IL28B CC allele is significantly higher in Koreans than Caucasians. ${ }^{25-27}$ Although further studies are needed to determine the specifics of different response rates between Korean and Western patients with HCV genotype 2 infection, the combination of sofosbuvir plus weight-based ribavirin is the only approved standard care for the treatment of Korean patients with chronic HCV genotype 2 infection for these reasons.

In this multicenter study, 161 of 163 patients completed 12-16 weeks treatment adjusted for presence of cirrhosis, and they all

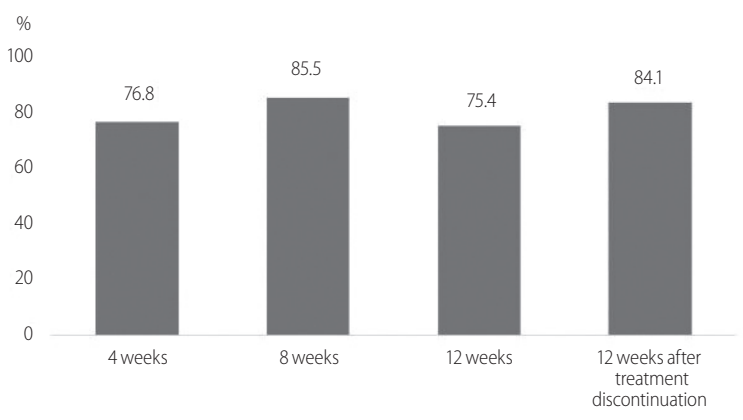

Figure 3. The ALT normalization rate. We analyzed 69 patients who showed ALT level higher than $40 \mathrm{IU} / \mathrm{L}$ to determine the ALT normalization rate. $\mathrm{ALT}$, alanine aminotransferase.

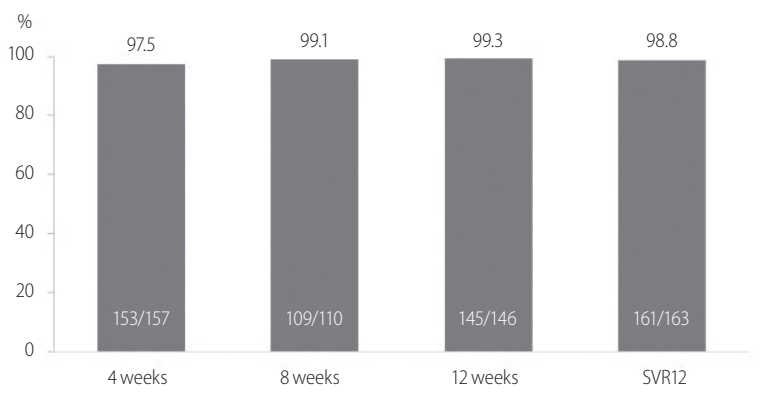

Figure 4. Virologic response at 4, 8, and 12 weeks and SVR12 in 163 patients enrolled in the present study. Two patients failed to achieve the SVR12. SVR12, sustained virologic response 12 weeks after t reatment discontinuation. 


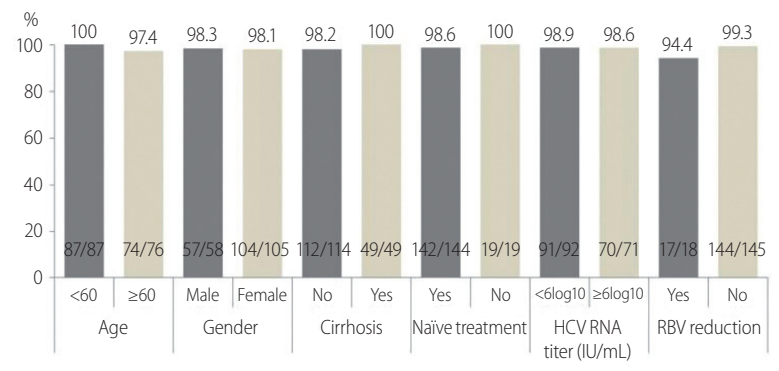

Figure 5. SVR12 according to baseline age, sex, presence of cirrhosis, treatment history, pretreatment HCV RNA level, and RBV dose reduction in 163 patients. There was no significant difference between groups. SVR12, sustained virologic response 12 weeks after t reatment discontinuation; $H C V$, hepatitis C virus; $R B V$, ribavirin.

were tested for the SVR12. One patient stopped the treatment because of severe adverse event. Another patient took medications only 8 weeks due to economic problem, but she achieved SVR12. Virologic response was prompt and 4 weeks after treatment, HCV RNA non-detection rate was equal to $97.5 \%$. SVR12 was also remarkable: $98.8 \%$ of patients (161/163) showed a SVR12 rate in this study. The present study included treatment-experienced patients (11.7\%) and patients with cirrhosis (30.1\%). The virologic response was influenced neither by treatment history nor by presence of cirrhosis. Eighteen patients with cirrhosis have taken 12 weeks treatment and they all achieved SVR12. There was no definite guideline about choosing 12 weeks or 16 weeks treatment in patients with cirrhosis. Considering our results, although a small number, 12 weeks treatment might be enough to achieve the SVR12.

Only one patient failed to achieve SVR12 although she completed 12 weeks treatment. She was 74 years old and had no treatment history of HCV. We could not exactly know the factors which affected the treatment failure. Considering previously suggested factors, older age might be associated, but more data including failed patients should be needed.

Sofosbuvir and ribavirin are more convenient and trigger less adverse events than interferon-based therapy. Interferon-based regimens can be poorly tolerated and are in contraindication in many patients over 60 years of age with advanced liver disease. ${ }^{28-32}$ In contrast, DAAs can be used in almost all patients with HCV infection who are not eligible for conventional interferon-based treatment. ${ }^{8}$ Treatment with sofosbuvir plus ribavirin was well tolerated in all subgroups, including patients with cirrhosis and patients with treatment history. According to BOSON study, which was conducted in Western countries, the safety profile of sofosbuvir and ribavirin was similar in treatment-naive and treatment-experienced patients. ${ }^{33}$ The most common treatment-related adverse events were dizziness and anemia, which were both attributed to ribavirin in the present study. $18(11.0 \%)$ patients have seen their ribavirin dosage be reduced and one patient stopped the treatment because of severe anemia. The current guideline in Western countries recommend treatment regimens without ribavirin. The AASLD recommends glecaprevir plus pibrentasvir for 8 weeks or sofosbuvir plus velpatasvir for 12 weeks. ${ }^{6}$ The EASL recommend sofosbuvir plus velpatasvir for 12 weeks or sofsbuvir plus daclatasvir.? Considering the frequent and occasionally severe side effects of ribavirin, a treatment regimen excluding ribavirin should be tested and proposed in Korea, too.

One patient stopped the treatment due to financial issues. Currently, the cost of a HCV treatment with sofosbuvir for 12 weeks is over 6,000\$ in Korea. The high price of the drug is a barrier to proper treatment of HCV infection. For more patients to be treated, efforts must be dedicated to lowering the price of the treatment for the patients.

Even though we included many patients in multicenters, there are some limitations. First, all laboratory parameters such as HCV RNA titers, liver function tests were not tested on all patients every 4 weeks. HCV RNA undetection rate, ALT normalization rate could be changed because of skipped data. Second, adverse events might be missed because the present study were retrospectively analyzed. Third, long-term treatment effect such as improvement of LC, prevention of HCC has not been analyzed because we reviewed the medical record up to only 12 weeks post-treatment. But, considering the period that sofosbuvir was introduced in Korea, relatively many numbers of the enrolled patients would be meaningful. The present study could be helpful enough to decide the treatment regimen of HCV genotype 2 infection in Korea.

In conclusion, 12-16 weeks of treatment with sofosbuvir, once daily, and weight-based ribavirin, twice daily, was effective and well tolerated in both treatment-naive and treatment-experienced Korean patients with chronic HCV genotype 2 infection with or without cirrhosis.

\section{Author contributions}

SB Kim was the principal investigator and was responsible for desing of this study.

YM Kim, IH Song, SH Lee, HS Kim, TH Lee, YW Kang, SH Kim, BS Lee, HB Chae, MJ Song, JW Jang, SY Ko, JD Lee collected the data.

YM Kim and SB Kim analyzed the data statistically.

YM Kim and SB Kim wrote the the manuscript and critically revised it. 


\section{Conflicts of Interest}

SB Kim, SH Lee, BS Lee, JW Jang receives grants from Gilead Sciences. The other authors declare no conflicts of interest.

\section{REFERENCES}

1. Kim MN, Kim BK, Han KH. Hepatocellular carcinoma in patients with chronic hepatitis C virus infection in the Asia-Pacific region. J Gastroenterol 2013;48:681-688.

2. Kim DY, Kim IH, Jeong SH, Cho YK, Lee JH, Jin YJ, et al. A nationwide seroepidemiology of hepatitis $\mathrm{C}$ virus infection in South Korea. Liver Int 2013:33:586-594.

3. Jeong SH, Jang ES, Choi HY, Kim KA, Chung W, Ki M. Current status of hepatitis $C$ virus infection and countermeasures in South Korea. Epidemiol Health 2017;39:e2017017.

4. Kanda T, Imazeki F, Yokosuka O. New antiviral therapies for chronic hepatitis C. Hepatol Int 2010;4:548-561.

5. Kanda T, Imazeki F, Azemoto R, Yonemitsu Y, Mikami S, Kita K, et al. Response to peginterferon-alfa $2 \mathrm{~b}$ and ribavirin in Japanese patients with chronic hepatitis C genotype 2. Dig Dis Sci 2011;56:3335-3342.

6. The American Association for the Study of Liver Diseases and the Infectious Diseases Society of America Present. HCV Guidance: Recommendations for testing, managing, and treating hepatitis C. AASLD and IDSA web site, <http://www.hcvguidelines.org>. Accessed 21 Sep 2017.

7. European Association for the Study of the Liver. EASL recommendations on treatment of hepatitis C 2016. J Hepatol 2017;66:153-194.

8. Korean Association for the Study of the Liver. KASL clinical practice guidelines: management of hepatitis C. Clin Mol Hepatol 2016;22:76-139.

9. Lawitz E, Mangia A, Wyles D, Rodriguez-Torres M, Hassanein T, Gordon SC, et al. Sofosbuvir for previously untreated chronic hepatitis $C$ infection. N Engl J Med 2013;368:1878-1887.

10. Jacobson IM, Gordon SC, Kowdley KV, Yoshida EM, Rodriguez-Torres $M$, Sulkowski MS, et al. Sofosbuvir for hepatitis C genotype 2 or 3 in patients without treatment options. N Engl J Med 2013;368:18671877.

11. Zeuzem S, Dusheiko GM, Salupere R, Mangia A, Flisiak R, Hyland RH, et al. Sofosbuvir and ribavirin in HCV genotypes 2 and 3. N Engl J Med 2014;370:1993-2001.

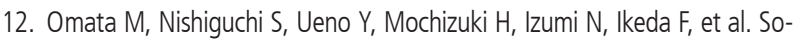
fosbuvir plus ribavirin in Japanese patients with chronic genotype $2 \mathrm{HCV}$ infection: an open-label, phase 3 trial. J Viral Hepat 2014;21:762-768.

13. Kao JH, Chien RN, Chang TT, Peng CY, Hu TH, Lo GH, et al. A phase 3b study of sofosbuvir plus ribavirin in Taiwanese patients with chronic genotype 2 hepatitis C virus infection. Liver Int 2016;36:1101-1107.

14. Lam AM, Murakami E, Espiritu C, Steuer HM, Niu C, Keilman M, et al.
PSI-7851, a pronucleotide of beta-D-2'-deoxy-2'-fluoro-2'-C-methyluridine monophosphate, is a potent and pan-genotype inhibitor of hepatitis C virus replication. Antimicrob Agents Chemother 2010;54:3187-3196.

15. Kanda T, Yokosuka O, Imazeki F, Tanaka M, Shino Y, Shimada H, et al. Inhibition of subgenomic hepatitis C virus RNA in Huh-7 cells: ribavirin induces mutagenesis in HCV RNA. J Viral Hepat 2004;11:479-487.

16. Oh DJ, Park YM, Seo YI, Lee JS, Lee JY. Prevalence of hepatitis C virus infections and distribution of hepatitis $C$ virus genotypes among Korean blood donors. Ann Lab Med 2012;32:210-215.

17. Cho EJ, Jeong SH, Han BH, Lee SU, Yun BC, Park ET. Hepatitis C virus (HCV) genotypes and the influence of HCV subtype $1 \mathrm{~b}$ on the progression of chronic hepatitis $\mathrm{C}$ in Korea: a single center experience. Clin Mol Hepatol 2012;18:219-224.

18. Kim YS, Ahn YO, Lee HS. Risk factors for hepatitis C virus infection among Koreans according to the hepatitis C virus genotype. J Korean Med Sci 2002;17:187-192.

19. García-Samaniego J, Romero M, Granados R, Alemán R, Jorge Juan M, Suárez $\mathrm{D}$, et al. Factors associated with early virological response to peginterferon- $\alpha$-2a/ribavirin in chronic hepatitis C. World J Gastroenterol 2013;19:1943-1952.

20. Bressler BL, Guindi M, Tomlinson G, Heathcote J. High body mass index is an independent risk factor for nonresponse to antiviral treatment in chronic hepatitis C. Hepatology 2003;38:639-644.

21. Chen JY, Lin CY, Wang CM, Lin YT, Kuo SN, Shiu CF, et al. IL28B genetic variations are associated with high sustained virological response (SVR) of interferon- $\alpha$ plus ribavirin therapy in Taiwanese chronic HCV infection. Genes Immun 2011;12:300-309.

22. Hsu CS, Hsu SJ, Chen HC, Tseng TC, Liu CH, Niu WF, et al. Association of IL28B gene variations with mathematical modeling of viral kinetics in chronic hepatitis $C$ patients with IFN plus ribavirin therapy. Proc Natl Acad Sci U S A 2011;108:3719-3724.

23. Ge D, Fellay J, Thompson AJ, Simon JS, Shianna KV, Urban TJ, et al. Genetic variation in IL28B predicts hepatitis $C$ treatment-induced viral clearance. Nature 2009;461:399-401.

24. Thomas DL, Thio CL, Martin MP, Qi Y, Ge D, O'Huigin C, et al. Genetic variation in IL28B and spontaneous clearance of hepatitis $C$ virus. Nature 2009;461:798-801.

25. Lyoo K, Song MJ, Hur W, Choi JE, Hong SW, Kim CW, et al. Polymorphism near the IL28B gene in Korean hepatitis C virus-infected patients treated with peg-interferon plus ribavirin. J Clin Virol 2011;52:363-366.

26. Jung YK, Kim JH, Ahn SM, Yang JW, Park SJ, Kim JW, et al. Role of interleukin 28B-related gene polymorphisms in chronic hepatitis $C$ and the response to antiviral therapy in Koreans. J Clin Gastroenterol 2013;47:644-650.

27. Kim SU, Song KJ, Chang HY, Shin EC, Park JY, Kim DY, et al. Association between IL28B polymorphisms and spontaneous clearance of hepatitis B virus infection. PLoS One 2013;8:e69166.

28. Höroldt B, Haydon G, O'Donnell K, Dudley T, Nightingale P, Mutimer 
D. Results of combination treatment with pegylated interferon and ribavirin in cirrhotic patients with hepatitis C infection. Liver Int 2006;26:650659 .

29. Carrión JA, Martínez-Bauer E, Crespo G, Ramírez S, Pérez-del-Pulgar $S$, García-Valdecasas JC, et al. Antiviral therapy increases the risk of bacterial infections in HCV-infected cirrhotic patients awaiting liver transplantation: a retrospective study. J Hepatol 2009;50:719-728.

30. Huang CF, Yang JF, Dai CY, Huang JF, Hou NJ, Hsieh MY, et al. Efficacy and safety of pegylated interferon combined with ribavirin for the treatment of older patients with chronic hepatitis C. J Infect Dis 2010;201:751-759.

31. Thabut D, Le Calvez S, Thibault V, Massard J, Munteanu M, Di Mar- tino $\mathrm{V}$, et al. Hepatitis $\mathrm{C}$ in 6,865 patients $65 \mathrm{yr}$ or older: a severe and neglected curable disease? Am J Gastroenterol 2006;101:12601267.

32. Nudo CG, Wong P, Hilzenrat N, Deschênes M. Elderly patients are at greater risk of cytopenia during antiviral therapy for hepatitis C. Can J Gastroenterol 2006;20:589-592.

33. Foster GR, Pianko S, Brown A, Forton D, Nahass RG, George J, et al. Efficacy of sofosbuvir plus ribavirin with or without peginterferon-alfa in patients with hepatitis $C$ virus genotype 3 infection and treatmentexperienced patients with cirrhosis and hepatitis C virus genotype 2 infection. Gastroenterology 2015;149:1462-1470. 